\title{
Life and death decisions by E2F-1
}

\author{
LA Bell ${ }^{1}$ and KM Ryan ${ }^{\star, 1}$ \\ 1 Tumour Cell Death Laboratory, Beatson Institute for Cancer Research, Cancer \\ Research UK Beatson Laboratories, Garscube Estate, Switchback Road, \\ Glasgow G61 1BD, UK \\ * Correspondence: KM Ryan, Tel: + 44-141-330-3655; \\ Fax: +44-141-942-6521; E-mail: k.ryan@ beatson.gla.ac.uk
}

Received 16.6.03; revised 06.8.03; accepted 06.8.03; published online 03.10.03 Edited by G. Melino

\section{Abstract}

Deregulation of the transcription factor E2F-1 is a common event in most human cancers. Paradoxically, E2F-1 has been shown to have the ability to induce both cell cycle progression and programmed cell death, leading potentially to both tumour-promoting as well as tumour-suppressive effects. Although the pathway to cell cycle progression seems straightforward with a number of growth-promoting E2F target genes having been described, the pathways to apoptosis are less well defined and more complex. The discovery that E2F-1 'knockout' mice are highly tumour prone has caused a recent surge in the number of reports relating to programmed cell death. This review focuses on these recent findings, highlighting the way in which they have increased our understanding of E2F-1-induced cell death, as well as indicating the questions that remain. Insight gained as to the role of this intriguing molecule in cancer and its potential for targeted therapy will also be discussed.

Cell Death and Differentiation (2004) 11, 137-142. doi:10.1038/

sj.cdd.4401324

Published online 3 October 2003

Keywords: E2F-1; cancer; programmed cell death

Abbreviations: E2F-1 to E2F-6, DNA-binding proteins; cdk, cyclin-dependent kinase; HDAC, histone deacetylases; SWI/ SNF, chromatin remodeling factors; SUV39H10, histone methyl transferase; DAP, death-associated protein

\section{Introduction}

In recent years we have come a long way in discerning the breakdown of normal cell mechanisms that results in tumour formation. Malignant transformation often involves combinations of mutations which, by necessity, are tissue and context specific, giving rise to a hugely disparate set of diseases. ${ }^{1}$ However, one property that all cancers share is the ability to proliferate beyond the normal limits and constraints. To do this the cell must acquire new properties, such as being able to deregulate cell proliferation and suppress cell death. ${ }^{2}$
The survival of long-lived multicellular organisms is dependent on allowing proliferation of their cells when needed, while at the same time suppressing the deregulated growth of mutated cells. Normal somatic cells are totally dependent on continuous receipt of appropriate mitogenic signals for their proliferation. There is also a network of inhibitory factors that serve to check the proliferative response to mitogens and must be overcome for cell cycle entry and proliferation. ${ }^{3}$ If appropriate signals are not received when cell cycle progression is stimulated, a stress response ensues driving the cell towards programmed cell death (apoptosis) ${ }^{4} \mathrm{~A}$ key factor controlling these processes is a nuclear protein called E2F-1.

\section{E2Fs in Cell Cycle Control}

E2F-1 belongs to the E2F family of DNA-binding proteins (E2F-1 to E2F-6), which are central regulators of cell cycle progression. ${ }^{5,6}$ These proteins function as heterodimers with members of the DP family (DP1 and DP2), with the DNAbinding specificity being determined by the E2F subunit. The E2F family regulates overlapping sets of target genes and all contain related DNA binding and dimerisation domains. All the members of the family, except E2F-6, also contain a transactivation domain. Based on structure, transcriptional properties and association with pocket proteins, the E2F family can be divided into three distinct groups. E2F-1, E2F-2 and E2F-3 associate preferentially with $\mathrm{pRb}$ (a product of the retinoblastoma susceptibility gene), and are potent transcriptional activators. ${ }^{7}$ E2F-4, which associates with $\mathrm{pRb}$, and its related 'pocket' proteins p107 and p130, and E2F-5 that associates with $\mathrm{p} 130$, seem to be primarily involved in the active repression of E2F-responsive genes. ${ }^{7}$ E2F- 6 does not interact with pocket proteins and functions as a negative regulator of E2F-dependent transcription via complexing with chromatin modifiers. ${ }^{8-10}$

In untransformed cells, the ability of $\mathrm{pRb}$ to bind to E2F is regulated by its cell-cycle-dependent phosphorylation. ${ }^{11} \mathrm{pRb}$ is unphosphorylated during the G0 and early G1 stages of the cell cycle, and this form binds and inhibits E2F (Figure 1). Mitogenic growth factors induce the sequential activation of the cyclin-dependent kinase (cdk) complexes, cdk4/cdk6cyclin D and cdk2-cyclin E, which then phosphorylate pRB and causes it to become dissociated from E2F. ${ }^{12,13}$ The resultant activation of E2F-responsive genes (e.g. those involved in DNA synthesis, cell cycle control, pocket protein expression, etc.) in late G1 seems to be sufficient to commit the cells to initiate DNA replication. ${ }^{14}$ Conversely, many growth-inhibitory signals such as those from the TGF $\beta$ family and from the p53/p21 checkpoint pathway mediate their effects by blocking phosphorylation of $p R b$. In this way, $p R b$ monitors both positive and negative growth signals and determines if the cell should divide. ${ }^{15,16}$ 


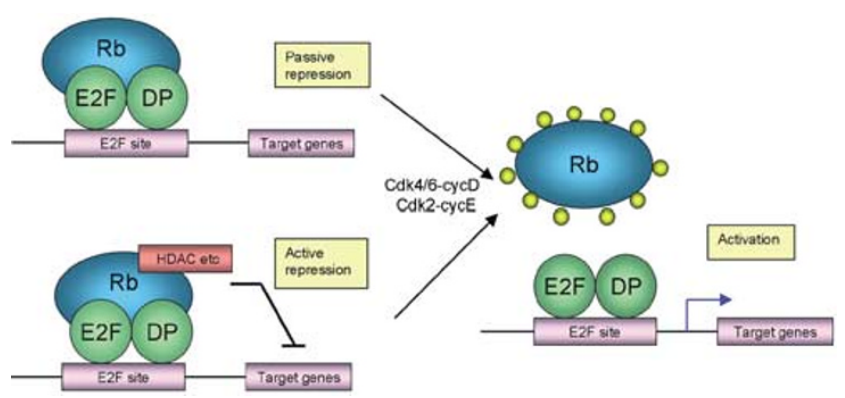

Figure $1 \mathrm{pRb}$ binds to an E2F-DP complex in cells in the G0/G1 stage of the cell cycle. This leads to repression of E2F-responsive genes, firstly by inhibiting E2F from activating transcription by binding its transactivation domain, and secondly by active repression where it recruits factors such as HDAC, which modifies histone tails and therefore facilitates nucleosome packaging. Cdk4/6cyclin $\mathrm{D}$ and cdk 2-cyclin $\mathrm{E}$ phosphorylate $\mathrm{pRb}$ and cause it to release $\mathrm{E} 2 \mathrm{~F}$, activating E2F-responsive genes

In its unphosphorylated state, $\mathrm{pRb}$ can regulate E2Fresponsive genes through two distinct mechanisms. First, $\mathrm{pRb}$ binds to an 18 amino-acid motif within the transactivation domain of E2F, blocking the ability of E2F to recruit the basic transcriptional machinery. ${ }^{17,18}$ E2F in this context is considered a 'passive' repressor as it can occupy E2F DNA-binding sites, but cannot activate gene expression. Second, the $p R b-$ E2F complex, while still bound to DNA, recruits various factors, for example, histone deacetylases (HDACs), SWI/ SNF, Polycomb group proteins and histone methyl transferase (SUV39H10), which are able to switch off transcription and as a result effect 'active' repression (Figure 1). ${ }^{10,19-21}$ The relative importance of each of these transcriptional mechanisms to the functions of E2Fs is as yet not completely defined and is an area that is duly receiving intense investigation.

\section{A Role in Cancer}

E2F was originally discovered as a cellular component that is required for the early region transforming protein $(E 1 A)$ of adenovirus to mediate transcriptional activation of the viral E2 promoter. $^{22}$ Subsequent studies have shown that E2F controls the transcription of cellular genes that are essential for cell division, such as enzymes involved in the biosynthesis of nucleotides. ${ }^{23}$ In the 1990s, Nevins et $a^{24}$ deduced how E2F is regulated in normal cells by determining the mechanism of E2F activation by E1A. E1A caused a cellular protein to dissociate from E2F, which led them to show that E2F is inhibited by its association with $\mathrm{Rb}$. This early observation that E2F was deregulated by a transforming virus was the first indication that E2F may be associated with cancer. It was subsequently found that $\mathrm{Rb}$ is also targeted by other viral oncoproteins, including SV40 large T antigen and E7 proteins from 'high-risk' human papilloma viruses. ${ }^{25}$ It is now considered that deregulation of E2F is an event in most, if not all, cancers. As well as viral infection, this can occur by loss or mutation of $\mathrm{Rb}$, or more often through the upregulation of the cdk/cyclin complexes that phosphorylate $\mathrm{pRb}$ or through loss of the cdk inhibitor, p16. Surprisingly, however, E2F itself is rarely found to be mutated. ${ }^{26,27}$

\section{Oncogene or Tumour Suppressor?}

In light of their frequent deregulation, what is the role of E2Fs in tumour development? Studies on the best characterised $\mathrm{E} 2 \mathrm{~F}, \mathrm{E} 2 \mathrm{~F}-1$, have indicated that it may have a unique role compared to other E2Fs, showing characteristics of both an oncogene and a tumour suppressor. ${ }^{28}$ Several lines of evidence suggest that E2F-1 has the potential to function at an oncogene, promoting the proliferation of cells beyond their normal constraints. ${ }^{29}$ It is an important part of the circuitry that commits cells to progression through the G1 phase, after which the cell is committed to complete the rest of the cell cycle. As eluded to earlier, many genes that are regulated in a cell-specific manner have E2F-binding sites as their promoters, and in some cases E2F-1 has been demonstrated to induce their expression directly. Some of these gene products play a direct regulatory role in the cell cycle, for example, Cdc2, cdc25a and cyclin $E^{30-32}$ As well as this, forced expression of E2F-1, as with E2F-2 and E2F-3, in quiescent cells is sufficient to induce entry into DNA synthesis, and each of these E2Fs can function as oncogenes in transforming assays. ${ }^{33,34}$ It was amazing, therefore, to find that targeted deletion of the E2F-1 gene in mice resulted in animals that spontaneously developed tumours in a number of tissues. ${ }^{35}$ Although a surprise, this observation gave credence to previous studies that had indicated a role for E2F-1 in programmed cell death. Enforced expression of E2F-1 in vitro had been shown not only to cause cell cycle progression but also cause apoptosis in a number of cell types (Figure 2). ${ }^{36,37}$ In addition, apoptosis as a result of $\mathrm{Rb}$ deletion in mice was shown, by the generation of 'double' knockout mice $\left(\mathrm{Rb}^{-1-}\right.$, $\mathrm{E} 2 \mathrm{~F}-1^{-1-}$ ), to be dependent on E2F-1. ${ }^{38}$

For some time, this apoptotic activity of E2F-1 was thought to be similar to that described for another cancer-related protein, c-Myc. ${ }^{39}$ The elevation of c-Myc occurs in many tumours resulting in potent growth promotion. ${ }^{40}$ This effect of c-Myc can, however, only occur if the cell is also receiving appropriate survival signals, for example, IGF-1. ${ }^{41}$ If not, deregulation of c-Myc will cause programmed cell death. ${ }^{42}$ These findings resulted in the 'conflict of signals' model for oncogene activation, indicating that a safeguard mechanism exists within cells to protect against inappropriate growth promotion. This model, however, does not completely hold true for E2F-1 as mutants of E2F-1 have been described, which while unable to promote cell cycle progression, retain the ability to induce programmed cell death. ${ }^{43,44}$ As a result, interest in the apoptotic function of E2F-1 has resurged and numerous recent studies have provided insights into its deathpromoting activities.

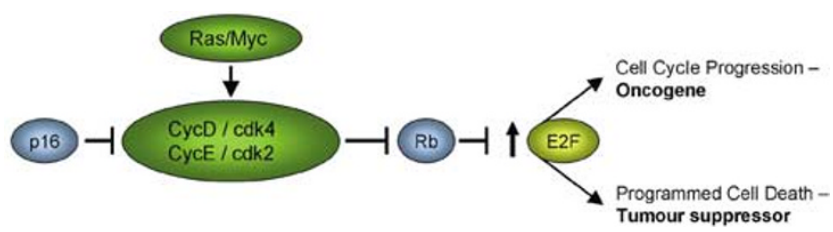

Figure 2 As a result of its upstream activation in tumours and its ability to induce both cell cycle progression and apoptosis, E2F-1 can have both oncogenic- and tumour-suppressive effects. Green factors: upregulated in cancer, blue factors: lost or mutated in cancer 


\section{Multiple Roads to Cell Death from E2F-1}

E2F-1 is capable of inducing apoptosis via several mechanisms (Figure 3). Both overexpression experiments and mutant mouse models of E2F-1 have shown that apoptosis can occur by mechanisms either dependent or independent of the tumour suppressor p53. The p53-dependent mechanism involves transactivation of the p14ARF protein by E2F-1. This can occur either directly through the transactivation of an E2Fbinding site in the ARF promoter - an effect that can be augmented by oncogenic Ras, or indirectly through the activation of death-associated protein (DAP) kinase. ${ }^{45-48}$ p53 regulation occurs largely at the level of protein stability and in normal unstressed cells, p53 is kept at a low level via a negative feedback loop in which p53 induces the transcription of HDM-2 (MDM2 in mice), which in turn binds to p53 and mediates its degradation. ${ }^{49,50} \mathrm{E} 2 \mathrm{~F}-1$ can stabilise $\mathrm{p} 53$ via the induction of the p14ARF protein, which functions by binding directly to HDM-2 and preventing its degradation of $p 53 .{ }^{51,52}$ As a result, depending on other signals being received by the cell at that time, this can result in E2F-1 directed, p53dependent cell death that, to a point, represents death by a 'conflict of signals' mechanism.

In cell types lacking p53, for example, Saos-2 oesteosarcoma cells, E2F-1 has still been shown to be an effective death inducer. In this situation, the p53 family member, p73, has been shown to play a role in E2F-1-induced cell death. ${ }^{53,54}$ E2F-1 directly activates the transcription of p73 leading to the activation of its target genes (some of which are shared with p53) and apoptosis. ${ }^{55}$ p73 is also able to bind to MDM-2, but is not degraded and so cannot be stabilised by ARF expression. ${ }^{56}$ This provides a direct mechanism for E2F1 -induced cell death, and although p73 is not frequently mutated in human tumours, methylation-dependent silencing has been reported in haematological malignancies. ${ }^{57}$ Moreover, it has recently been shown that several tumour-derived mutants of p53 that are often retained in cancer are able to bind and inactivate p73, thereby circumventing the necessity to mutate p73 per se. ${ }^{58}$ This process reduces chemosensitivity and adds more weight to the fact that E2F-1-induced apoptosis is an important tumour-suppressive mechanism as well a prognostic indicator of therapeutic success. ${ }^{59,60}$

Another mechanism of E2F-1-induced apoptosis is via the inhibition of antiapoptotic signalling. The two main apoptotic pathways in the cell have been defined as the mitochondrial

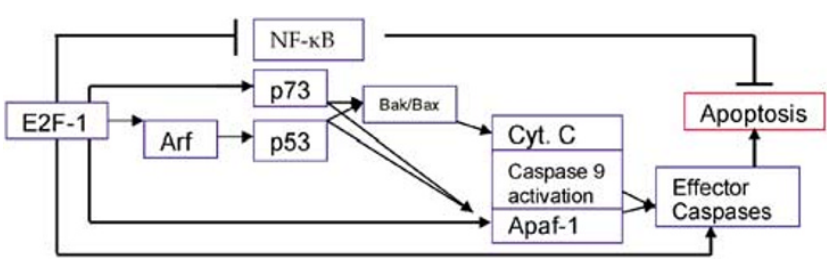

Figure 3 Routes through which E2F-1 can induce apoptosis. E2F-1 can induce cell death by activating the p53 family member $p 73$, or by stabilising the levels of p53 by transactivating the ARF tumour suppressor, with both pathways leading to the activation of caspase 9 . In addition, E2F-1 can induce cell death by talking to components of the cell machinery (i.e. Apaf- 1 and caspase 7) directly, or by suppressing antiapoptotic signals such as the activation of NF- $\kappa \mathrm{B}$ pathway and the death receptor pathway. ${ }^{61}$ The death receptor pathway activates a caspase cascade in response to external ligands activating the members of the tumour necrosis factor receptor super-family. These receptors have conserved protein-protein binding domains termed death domains, and recruit procaspases such as caspase 8 . Cleavage of these procaspases to active forms leads to the subsequent activation of effector caspases and apoptosis. Ligand binding does not always end in cell death, since some of the receptors also activate caspase independent signalling pathways that block apoptosis. The NF- $\kappa$ B family of transcription factors regulate apoptosis in response to many stimuli. ${ }^{62}$ The activation of NF- $\kappa \mathrm{B}$ can lead to tumour cell proliferation, invasion, angiogenesis and metastasis, therefore suppression of NF- $\kappa$ B in tumours may provide an additional target for prevention of cancer. ${ }^{63}$ In most cases, NF- $\kappa$ B functions as a survival signal, for example, the activation of TNFR results in the activation of NF- $\kappa \mathrm{B}$ via Traf2, which contributes to the inhibition of cell death. ${ }^{64}$ E2F-1 can downregulate Traf2 protein levels and therefore inhibit the activation of antiapoptotic signals, such as NF- $\kappa \mathrm{B}$ in response to $\mathrm{TNF} \alpha{ }^{65}$ It is interesting to note that this effect, similar to E2F-1's ability to inhibit transformation, does not require E2F-1's transactivation domain. ${ }^{65}$ The extent, however, to which this mechanism is involved in tumour suppression by E2F-1 is very interesting, but has yet to be determined.

In contrast to the role of NF- $\kappa \mathrm{B}$ following TNF $\alpha$ treatment, during cell death induced by $\mathrm{p} 53, \mathrm{NF}-\kappa \mathrm{B}$ has a surprising proapoptotic role. ${ }^{66}$ It has been suggested that NF- $\kappa$ B may be a good chemotherapeutic target; however, the inhibition of $\mathrm{NF}-\kappa \mathrm{B}$ following treatment with chemotherapeutic drugs would affect apoptosis differently depending on the p53 status of the cell - causing more cell death in p53 null or defective cells and less death in wild-type p53 cells. Dominant-negative forms of $\mathrm{NF}-\kappa \mathrm{B}$-inducing kinase (NIK) have been shown to enhance TNF $\alpha$-induced apoptosis in p53inducible Saos cells where there is no expression of $p 53$, but have no effect on p53-induced death in the same cells. ${ }^{66}$ This shows that p53 and TNF $\alpha$ utilize distinct pathways to activate $\mathrm{NF}-\kappa \mathrm{B}$ and presents possible targets for therapeutic intervention depending on the p53 status of the cells to be treated. Interestingly, NIK has recently been shown to be a transcriptional target of E2F-1, although the precise effect this may have on apoptosis and in particular the regulation of Traf-2 by $\mathrm{E} 2 \mathrm{~F}-1$ is yet to be ascertained. ${ }^{67} \mathrm{E} 2 \mathrm{~F}-1$ has also been shown to activate the expression of another kinase, PKR, leading to phosphorylation of its downstream target, the translation initiation factor, elF-2 $\alpha$ and subsequent apoptosis. ${ }^{68}$ Although this factor has previously been reported to interact with NF$\kappa \mathrm{B}$, its involvement in cell death induced by E2F-1 appears to be independent of $\mathrm{NF}-\kappa \mathrm{B}$ as well as p53 and p73. It is interesting to speculate that, since translation is known to be regulated by the insulin signalling pathway, whether factors in this pathway, for instance, mTOR are involved in regulating E2F-1 and E2F-1-induced programmed cell death. ${ }^{69,70}$ It has to be kept in mind though that even once the involvement with $\mathrm{E} 2 \mathrm{~F}-1$ is elucidated, these signalling pathways affect many factors and how they all integrate to determine the fate of the cell is undoubtedly going to be complex and situation dependent. 
Perhaps more simple to understand are a number of reports that have recently implicated E2F-1 as being a regulator of factors intrinsic to the apoptotic process, for example, apoptosis protein-activating factor (Apaf-1). ${ }^{71,72}$ When induced, Apaf-1 assembles with cytochrome $c$, a mitochondrial signal released on receipt of apoptotic signals, and activates caspase 9 leading to the activation of downstream effector caspases eventually leading to apoptosis (Figure 3). ${ }^{73}$ Although the death receptor and the Apaf pathways can be thought of as distinct, there is accumulating evidence that crosstalk occurs between all the different pathways, so the complex pattern of signal interaction must first be determined before the effects of individual signals can be seen. ${ }^{74}$

In addition to Apaf-1, DNA microarray studies have demonstrated that ectopic expression of E2F-1 can also upregulate the expression of several members of the caspase family. ${ }^{75}$ Interestingly, an antiapoptotic member of the bcl-2 family, Mcl-1, has also been found to be affected by E2F-1, but by transcriptional repression rather than activation. ${ }^{76}$ This repression does not require the transactivation domain of E2F-1 and therefore, together with the involvement of Traf2 regulation, provides some explanation of how E2F-1-induced cell death can occur without target gene activation.

\section{Therapeutic Possibilities}

The processes involved in tumour formation present many targets for cancer therapies. As deregulated cell proliferation and inhibition of apoptosis are two of the 'hallmarks' of cancer development, ${ }^{2}$ they present two obvious targets for therapeutic intervention. Many existing cancer drugs interfere with the basic machinery of DNA synthesis or metabolism and induce tumour cell killing by utilising apoptotic pathways. ${ }^{77}$ The fact that many of these pathways are inactivated during tumour development can lead to existing therapies being compromised through de novo drug resistance. ${ }^{78}$ Most of the proteins, however, which are inactivated in this way, for example, p53 loss or PTEN activation, are relatively 'upstream' components of these pathways and their inactivation leaves the 'downstream' apoptotic mechanism functionally intact. This is exemplified, for example, by the observation that spontaneously regressing tumours exhibit an increased frequency of programmed cell death. ${ }^{79}$ Therefore, since apoptotic programmes can be manipulated to produce changes in cell death, the genes and proteins controlling apoptosis are drug targets with great potential. Due to the 'double-edged sword' nature of E2F-1 activation, in many tumours the pathways that link E2F-1 to apoptosis have been interrupted, for example, through the loss of p53 in addition to presumably other as yet unknown mechanisms. This disrupts the balance of apoptosis and proliferation that usually occurs, allowing proliferation without 'safeguard' apoptotic mechanisms to prevent tumorigenesis. The factors therefore that suppress E2F-1-induced apoptosis, or the downstream targets in E2F-1-induced apoptosis, could be key targets for therapeutic intervention. As a result, it is an exciting prospect to consider that recent insights into E2F-1-mediated cell death could possibly prove to be of clinical benefit. Its important to note though that an apoptotic role for E2F-1 in cancer is not absolute, and that loss of E2F-1, for example, in Mycmediated lymphomagenesis, does not necessarily lead to apoptosis resistance. ${ }^{80}$ In this situation, the inactivation of E2F-1 leads instead to the inhibition of the enhanced cell cycle progression caused by c-Myc, indicating that actually targeting E2F-1 itself may well be useful. The further investigation therefore of the role of E2F-1 in cell death and cell cycle progression, and the way in which it integrates with other factors during tumour development can only serve to enhance and refine the potential of targeting the E2F pathway for therapy design.

\section{Future Prospects}

The pathways involving E2F-1 and apoptosis are both multiple and interactive (Figure 3), and although many recent advances discussed here have shed much light on these processes, many questions still remain. An understating, for example, of how E2F-1 can induce cell death either without transcriptional activation or even through repression are two areas that as yet are only minimally studied and undoubtedly worthy of further investigation. In addition, what determines the choice of E2F-1 response following deregulation is also yet to be determined. A number of stress-responsive kinases, including ATM/ATR and Chk2, have recently been implicated in signalling to E2F. ${ }^{81,82}$ In line with a previous observation showing that E2F-1 is stress responsive, these kinases have been implicated in the upregulation of E2F-1 following cellular stress and in the regulation of E2F-1-mediated death. ${ }^{81-83}$ The tantalising prospect of being able to modulate an E2F response by targeting these signalling pathways ensures that it will be not be long before more information into this level of regulation will be presented.

Ultimately though, perhaps the biggest question that remains is what is the role of E2F-1 in human cancer? Although a genuine tumour-derived somatic cell mutation in E2F-1 has recently been described and the investigation of its activities could indeed prove rewarding, the lack of a panel of E2F-1 mutants makes discerning the role of E2F in tumour development more difficult to determine ${ }^{84}$ While the continued study of E2F-1-induced cell death will provide an insight on this issue, it must ultimately be kept in mind that although E2F lies at the core of very significant cell fate decisions, it forms only part of a complex matrix of cell signalling events and interactions. For example, a recent study looking at the role of E2F-1 in the response of keratinocytes to UVB irradiation in mouse skin unexpectedly showed that ${\mathrm{E} 2 \mathrm{~F} 1^{-1}}^{-}$mice exhibit enhanced apoptosis following exposure to UVB when compared to wild-type counterparts. ${ }^{85}$ Moreover, when these mice were crossed

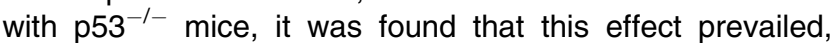
thereby reverting the apoptosis resistance caused by loss of p53 alone and indicating that E2F-1 must lie upstream of p53 in this response. ${ }^{85,86}$ Ultimately therefore, since this finding goes against so much of what we know about the role of E2F-1 in programmed cell death, it seems certain that the 'life and death decisions' by E2F-1 and whether it acts as an oncogene or tumour suppressor may well be context specific. 


\section{Acknowledgements}

We thank members of the Tumour Cell Death Laboratory for critical reading of the manuscript. Work within the laboratory is funded by Cancer Research UK, from whom KR receives a Senior Cancer Research Fellowship.

\section{References}

1. Marx J (1989) Many gene changes found in cancer. Science 246: 1386-1388

2. Hanahan $D$ and Weinberg RA (2000) The hallmarks of cancer. Cell 100: $57-70$

3. Evan GI and Vousden KH (2001) Proliferation, cell cycle and apoptosis in cancer. Nature 411: 342-348

4. Evan Gl, Brown L, Whyte M and Harrington E (1995) Apoptosis and the cell cycle. Curr. Opin. Cell Biol. 7: 825-834

5. Trimarchi JM and Lees JA (2002) Sibling rivalry in the E2F family. Nat. Rev. Mol. Cell. Biol. 3: 11-20

6. Stevaux $\mathrm{O}$ and Dyson NJ (2002) A revised picture of the E2F transcriptional network and RB function. Curr. Opin. Cell Biol. 14: 684-691

7. Dyson N (1998) The regulation of E2F by pRB-family proteins. Genes Dev. 12 : 2245-2262

8. Morkel M, Wenkel J, Bannister AJ, Kouzarides T and Hagemeier C (1997) An E2F-like repressor of transcription. Nature 390: 567-568

9. Trimarchi JM, Fairchild B, Verona R, Moberg K, Andon N and Lees JA (1998) $\mathrm{E} 2 \mathrm{~F}-6$, a member of the E2F family that can behave as a transcriptional repressor. Proc. Natl. Acad. Sci. USA 95: 2850-2855

10. Trimarchi JM, Fairchild B, Wen J and Lees JA (2001) The E2F6 transcription factor is a component of the mammalian Bmi1 - containing Polycomb complex. Proc. Natl. Acad. Sci. USA 98: 1519-1524

11. Mittnacht $S$ (1998) Control of pRB phosphorylation. Curr. Opin. Genet. Dev. 8: $21-27$

12. Lundberg AS and Weinberg RA (1998) Functional inactivation of the retinoblastoma protein requires sequential modification by at least two distinct cyclin-cdk complexes. Mol. Cell. Biol. 18: 753-761

13. Hinds PW, Mittnacht S, Dulic V, Arnold A, Reed SI and Weinberg RA (1992) Regulation of retinoblastoma protein functions by ectopic expression of human cyclins. Cell 70: 993-1006

14. Kowalik TF, DeGregori J, Schwarz JK and Nevins JR (1995) E2F1 overexpression in quiescent fibroblasts leads to induction of cellular DNA synthesis and apoptosis. J. Virol. 69: 2491-2500

15. Schwarz JK, Bassing CH, Kovesdi I, Datto MB, Blazing M, George S, Wang XF and Nevins JR (1995) Expression of the E2F1 transcription factor overcomes type beta transforming growth factor-mediated growth suppression. Proc. Natl. Acad. Sci. USA 92: 483-487

16. Hickman ES, Bates S and Vousden KH (1997) Perturbation of the p53 response by human papillomavirus type 16 E7. J. Virol. 71: 3710-3718

17. Flemington EK, Speck SH and Kaelin Jr WG (1993) E2F-1-mediated transactivation is inhibited by complex formation with the retinoblastoma susceptibility gene product. Proc. Natl. Acad. Sci. USA 90: 6914-6918

18. Helin K, Harlow E and Fattaey A (1993) Inhibition of E2F-1 transactivation by direct binding of the retinoblastoma protein. Mol. Cell. Biol. 13: 6501-6508

19. Ferreira R, Naguibneva I, Mathieu M, Ait-Si-Ali S, Robin P, Pritchard LL and Harel-Bellan A (2001) Cell cycle-dependent recruitment of HDAC-1 correlates with deacetylation of histone $\mathrm{H} 4$ on an $\mathrm{Rb}-\mathrm{E} 2 \mathrm{~F}$ target promoter. EMBO Rep. 2: 794-799

20. Trouche D, Le Chalony C, Muchardt C, Yaniv M and Kouzarides T (1997) RB and hbrm cooperate to repress the activation functions of E2F1. Proc. Natl. Acad. Sci. USA 94: 11268-11273

21. Robertson KD, Ait-Si-Ali S, Yokochi T, Wade PA, Jones PL and Wolffe AP (2000) DNMT1 forms a complex with Rb, E2F1 and HDAC1 and represses transcription from E2F-responsive promoters. Nat. Genet. 25: 338-342

22. Kovesdi I, Reichel R and Nevins JR (1986) Identification of a cellular transcription factor involved in E1A trans-activation. Cell 45: 219-228

23. Slansky JE, Li Y, Kaelin WG and Farnham PJ (1993) A protein synthesisdependent increase in E2F1 mRNA correlates with growth regulation of the dihydrofolate reductase promoter. Mol. Cell. Biol. 13: 1610-1618
24. Chellappan SP, Hiebert S, Mudryj M, Horowitz JM and Nevins JR (1991) The E2F transcription factor is a cellular target for the RB protein. Cell 65 : 1053-1061

25. Chellappan S, Kraus VB, Kroger B, Munger K, Howley PM, Phelps WC and Nevins JR (1992) Adenovirus E1A, simian virus 40 tumor antigen, and human papillomavirus $\mathrm{E} 7$ protein share the capacity to disrupt the interaction between transcription factor E2F and the retinoblastoma gene product. Proc. Natl. Acad. Sci. USA 89: 4549-4553

26. Harbour JW, Lai SL, Whang-Peng J, Gazdar AF, Minna JD and Kaye FJ (1988) Abnormalities in structure and expression of the human retinoblastoma gene in SCLC. Science 241: 353-357

27. Hall M and Peters G (1996) Genetic alterations of cyclins, cyclin-dependent kinases, and Cdk inhibitors in human cancer. Adv. Cancer Res. 68: 67-108

28. Pierce AM, Schneider-Broussard R, Gimenez-Conti IB, Russell JL, Conti CJ and Johnson DG (1999) E2F1 has both oncogenic and tumor-suppressive properties in a transgenic model. Mol. Cell. Biol. 19: 6408-6414

29. Johnson DG, Schwarz JK, Cress WD and Nevins JR (1993) Expression of transcription factor E2F1 induces quiescent cells to enter $S$ phase. Nature 365 : 349-352

30. DeGregori J, Kowalik T and Nevins JR (1995) Cellular targets for activation by the E2F1 transcription factor include DNA synthesis- and G1/S-regulatory genes. Mol. Cell. Biol. 15: 4215-4224

31. Vigo E, Muller H, Prosperini E, Hateboer G, Cartwright $P$, Moroni MC and Helin $K$ (1999) CDC25A phosphatase is a target of E2F and is required for efficient E2F-induced S phase. Mol. Cell. Biol. 19: 6379-6395

32. Ohtani K, DeGregori J and Nevins JR (1995) Regulation of the cyclin E gene by transcription factor E2F1. Proc. Natl. Acad. Sci. USA 92: 12146-12150

33. Lukas J, Petersen BO, Holm K, Bartek J and Helin K (1996) Deregulated expression of E2F family members induces S-phase entry and overcomes p16INK4A-mediated growth suppression. Mol. Cell. Biol. 16: 1047-1057

34. Johnson DG, Cress WD, Jakoi L and Nevins JR (1994) Oncogenic capacity of the E2F1 gene. Proc. Natl. Acad. Sci. USA 91: 12823-12827

35. Yamasaki L, Jacks T, Bronson R, Goillot E, Harlow E and Dyson NJ (1996) Tumor induction and tissue atrophy in mice lacking E2F-1. Cell 85: 537-548

36. Shan B and Lee WH (1994) Deregulated expression of E2F-1 induces S-phase entry and leads to apoptosis. Mol. Cell. Biol. 14: 8166-8173

37. Wu X and Levine AJ (1994) p53 and E2F-1 cooperate to mediate apoptosis. Proc. Natl. Acad. Sci. USA 91: 3602-3606

38. Tsai KY, Hu Y, Macleod KF, Crowley D, Yamasaki L and Jacks T (1998) Mutation of E2f-1 suppresses apoptosis and inappropriate $S$ phase entry and extends survival of Rb-deficient mouse embryos. Mol. Cell. 2: 293-304

39. Matsumura I, Tanaka H and Kanakura Y (2003) E2F1 and c-Myc in cell growth and death. Cell Cycle 2: 333-338

40. Dang CV, Resar LM, Emison E, Kim S, Li Q, Prescott JE, Wonsey D and Zeller K (1999) Function of the c-Myc oncogenic transcription factor. Exp. Cell. Res. 253: $63-77$

41. Harrington EA, Bennett MR, Fanidi A and Evan GI (1994) C-Myc-induced apoptosis in fibroblasts is inhibited by specific cytokines. EMBO J. 13: 3286-3295

42. Evan Gl, Wyllie AH, Gilbert CS, Littlewood TD, Land H, Brooks M, Waters CM, Penn LZ and Hancock DC (1992) Induction of apoptosis in fibroblasts by c-myc protein. Cell 69: 119-128

43. Phillips AC, Bates S, Ryan KM, Helin K and Vousden KH (1997) Induction of DNA synthesis and apoptosis are separable functions of E2F-1. Genes Dev. 11: 1853-1863

44. Hsieh JK, Fredersdorf S, Kouzarides T, Martin K and Lu X (1997) E2F1induced apoptosis requires DNA binding but not transactivation and is inhibited by the retinoblastoma protein through direct interaction. Genes Dev. 11: 1840-1852

45. Bates S, Phillips AC, Clark PA, Stott F, Peters G, Ludwig RL and Vousden KH (1998) p14ARF links the tumour suppressors RB and p53. Nature 395: $124-125$

46. de Stanchina E, McCurrach ME, Zindy F, Shieh SY, Ferbeyre G, Samuelson AV, Prives C, Roussel MF, Sherr CJ and Lowe SW (1998) E1A signaling to p53 involves the p19(ARF) tumor suppressor. Genes Dev. 12: 2434-2442

47. Berkovich $E$, Lamed $Y$ and Ginsberg $D$ (2003) E2F and Ras synergize in transcriptionally activating p14ARF expression. Cell Cycle 2: 127-133 
48. Raveh T, Droguett G, Horwitz MS, DePinho RA and Kimchi A (2001) DAP kinase activates a p19ARF/p53-mediated apoptotic checkpoint to suppress oncogenic transformation. Nat. Cell Biol. 3: 1-7

49. Kubbutat MH, Jones SN and Vousden KH (1997) Regulation of p53 stability by Mdm2. Nature 387: 299-303

50. Haupt $Y$, Maya R, Kazaz A and Oren M (1997) Mdm2 promotes the rapid degradation of p53. Nature 387: 296-299

51. Pomerantz J, Schreiber-Agus N, Liegeois NJ, Silverman A, Alland L, Chin L, Potes J, Chen K, Orlow I, Lee HW, Cordon-Cardo C and DePinho RA (1998) The Ink4a tumor suppressor gene product, p19Arf, interacts with MDM2 and neutralizes MDM2's inhibition of p53. Cell 92: 713-723

52. Zhang $Y$, Xiong $Y$ and Yarbrough WG (1998) ARF promotes MDM2 degradation and stabilizes p53: ARF-INK4a locus deletion impairs both the $\mathrm{Rb}$ and $\mathrm{p} 53$ tumor suppression pathways. Cell 92: 725-734

53. Irwin M, Marin MC, Phillips AC, Seelan RS, Smith DI, Liu W, Flores ER, Tsai KY, Jacks T, Vousden KH and Kaelin Jr WG (2000) Role for the p53 homologue p73 in E2F-1-induced apoptosis. Nature 407: 645-648

54. Lissy NA, Davis PK, Irwin M, Kaelin WG and Dowdy SF (2000) A common E2F1 and p73 pathway mediates cell death induced by TCR activation. Nature 407: 642-645

55. Yang A and McKeon F (2000) P63 and P73: P53 mimics, menaces and more. Nat. Rev. Mol. Cell. Biol. 1: 199-207

56. Balint E, Bates S and Vousden KH (1999) Mdm2 binds p73 alpha without targeting degradation. Oncogene 18: 3923-3929

57. Martinez-Delgado B, Melendez B, Cuadros M, Jose Garcia M, Nomdedeu J, Rivas C, Fernandez-Piqueras $\mathrm{J}$ and Benitez J (2002) Frequent inactivation of the p73 gene by abnormal methylation or LOH in non-Hodgkin's lymphomas. Int. J. Cancer 102: 15-19

58. Di Como CJ, Gaiddon C and Prives C (1999) p73 function is inhibited by tumorderived p53 mutants in mammalian cells. Mol. Cell. Biol. 19: 1438-1449

59. Bergamaschi D, Gasco M, Hiller L, Sullivan A, Syed N, Trigiante G, Yulug I, Merlano M, Numico G, Comino A, Attard M, Reelfs O, Gusterson B, Bell AK, Heath V, Tavassoli M, Farrell PJ, Smith P, Lu X and Crook T (2003) p53 polymorphism influences response in cancer chemotherapy via modulation of p73-dependent apoptosis. Cancer Cell 3: 387-402

60. Irwin MS, Kondo K, Marin MC, Cheng LS, Hahn WC and Kaelin WG (2003) Chemosensitivity linked to p73 function. Cancer Cell 3: 403-410

61. Green DR and Evan GI (2002) A matter of life and death. Cancer Cell 1: 19-30

62. Barkett M and Gilmore TD (1999) Control of apoptosis by Rel/NF-kappaB transcription factors. Oncogene 18: 6910-6924

63. Orlowski AS and Baldwin Jr AS (2002) NF-kappaB as a therapeutic target in cancer. Trends Mol. Med. 8: 385-389

64. Chen G and Goeddel DV (2002) TNF-R1 signaling: a beautiful pathway Science 296: 1634-1635

65. Phillips AC, Ernst MK, Bates S, Rice NR and Vousden KH (1999) E2F-1 potentiates cell death by blocking antiapoptotic signaling pathways. Mol. Cell. 4: 771-781

66. Ryan KM, Ernst MK, Rice NR and Vousden KH (2000) Role of NF-kappaB in p53-mediated programmed cell death. Nature 404: 892-897

67. Stanelle J, Stiewe T, Theseling CC, Peter M and Putzer BM (2002) Gene expression changes in response to E2F1 activation. Nucleic Acids Res. 30: 1859-1867
68. Vorburger SA, Pataer A, Yoshida K, Barber GN, Xia W, Chiao P, Ellis LM, Hung MC, Swisher SG and Hunt KK (2002) Role for the double-stranded RNA activated protein kinase PKR in E2F-1-induced apoptosis. Oncogene 21: $6278-6288$

69. Gingras AC, Raught B and Sonenberg N (2001) Regulation of translation initiation by FRAP/mTOR. Genes Dev. 15: 807-826

70. Cherkasova VA and Hinnebusch AG (2003) Translational control by TOR and TAP42 through dephosphorylation of elF2alpha kinase GCN2. Genes Dev. 17: 859-872

71. Furukawa $Y$, Nishimura N, Satoh M, Endo H, Iwase S, Yamada H, Matsuda M, Kano $Y$ and Nakamura M (2002) Apaf-1 is a mediator of E2F-1-induced apoptosis. J. Biol. Chem. 277: 39760-39768

72. Moroni MC, Hickman ES, Denchi EL, Caprara G, Colli E, Cecconi F, Muller H and Helin K (2001) Apaf-1 is a transcriptional target for E2F and p53. Nat. Cell Biol. 3: $552-558$

73. Cain K, Bratton SB and Cohen GM (2002) The Apaf-1 apoptosome: a large caspase-activating complex. Biochimie 84: 203-214

74. Esposti MD (2002) The roles of Bid. Apoptosis 7: 433-440

75. Nahle Z, Polakoff J, Davuluri RV, McCurrach ME, Jacobson MD, Narita M, Zhang MQ, Lazebnik Y, Bar-Sagi D and Lowe SW (2002) Direct coupling of the cell cycle and cell death machinery by E2F. Nat. Cell. Biol. 4: 859-864

76. Croxton R, Ma Y, Song L, Haura EB and Cress WD (2002) Direct repression of the Mcl-1 promoter by E2F1. Oncogene 21: 1359-1369

77. Schmitt CA and Lowe SW (1999) Apoptosis and therapy. J. Pathol. 187: $127-137$

78. Johnstone RW, Ruefli AA and Lowe SW (2002) Apoptosis: a link between cancer genetics and chemotherapy. Cell 108: 153-164

79. Papac RJ (1990) Spontaneous regression of cancer. Conn. Med. 54: 179-182

80. Baudino TA, Maclean KH, Brennan J, Parganas E, Yang C, Aslanian A, Lees JA, Sherr CJ, Roussel MF and Cleveland JL (2003) Myc-mediated proliferation and lymphomagenesis, but not apoptosis, are compromised by E2f1 loss. Mol. Cell 11: 905-914

81. Lin WC, Lin FT and Nevins JR (2001) Selective induction of E2F1 in response to DNA damage, mediated by ATM-dependent phosphorylation. Genes Dev. 15: $1833-1844$

82. Stevens C, Smith L and La Thangue NB (2003) Chk2 activates E2F-1 in response to DNA damage. Nat. Cell Biol. 5: 401-409

83. Blattner C, Sparks A and Lane D (1999) Transcription factor E2F-1 is upregulated in response to DNA damage in a manner analogous to that of $p 53$ Mol. Cell. Biol. 19: 3704-3713

84. Gorgoulis VG, Zacharatos P, Mariatos G, Kotsinas A, Bouda M, Kletsas D, Asimacopoulos PJ, Agnantis N, Kittas C and Papavassiliou AG (2002) Transcription factor E2F-1 acts as a growth-promoting factor and is associated with adverse prognosis in non-small cell lung carcinomas. J. Pathol. 198: $142-156$

85. Wikonkal NM, Remenyik E, Knezevic D, Zhang W, Liu M, Zhao H, Berton TR, Johnson DG and Brash DE (2003) Inactivating E2f1 reverts apoptosis resistance and cancer sensitivity in Trp53-deficient mice. Nat. Cell Biol. 5 : $655-660$

86. La Thangue NB (2003) The yin and yang of E2F-1: balancing life and death. Nat. Cell Biol. 5: 587-589 